\title{
Ontological Perspectivism and Geographical Categorizations
}

\author{
Timothy Tambassi ${ }^{1}$ iD
}

Received: 1 May 2020 / Revised: 30 March 2021 / Accepted: 5 April 2021 /

Published online: 27 April 2021

(c) The Author(s) 2021

\begin{abstract}
According to ontological perspectivism, there can be, in principle, multiple and alternative perspectives on the world that can be sliced, systematized, and conceptualized in different ways. Surely, such an ontological position has many categorial implications, which may vary depending on different disciplinary contexts. This paper explores parts of these implications in the realm of geography. In particular, it aims at discussing the ontological categories that one might use to describe the geographical world in an overarching perspective - that is, the perspective that puts toether all the partial views coming from the different branches of the geographical investigation. We will see that if the overarching perspective is expected to include all the views on the geographical world, then such a perspective should be all-embracing in terms of contents and categories. This means that the overarching perspective might also comprehend inconsistencies that derive from how the various partial perspectives conceptualize differently the geographical world.
\end{abstract}

Keywords Applied ontology · Geographical perspectives · Geographical word · Geo-ontologies · Inventories of entities · Ontological categorizations · Ontological integrations $\cdot$ Ontological perspectivism

\section{Katherine Munn on (Geographical) Perspectives}

By paraphrasing the words of Katherine Munn, a geographical perspective may be conceived of as an act of cognitively partitioning the geographical world - that is, an act that draws a mental division between those things upon which we are focusing and those which fall outside our domain of interest (Munn, 2008: 12). Examples of (different) perspectives, within the geographical realm, might be:

Timothy Tambassi

timothy.tambassi@gmail.com

https://timothytambassi.wordpress.com/

1 Department of Science of Cultural Heritage, University of Salerno, via Giovanni Paolo II, 132,

84084 Fisciano, SA, Italy 
1.1 the various areas of investigation of geography as a discipline;

1.2 the different branches in which the geographical investigation can be split, such as human, physical, cultural, transport, economic geography, and so forth.

On this basis, physical geography can be regarded as a cognitive partition mainly focused on entities like deserts, seas and hills, but not on political boundaries or administrative units. Conversely, human geography would represent the act that mentally splits the geographical world in entities such as nations, regions and districts. ${ }^{1}$ In addition, transport geography pays particular attention to roads and streets, but less to postal districts or seabeds, and so on, according to other geographical areas of investigations and branches.

Distinguishing between 1.1 and 1.2 is not an accidental choice, as the two alternatives presume different ways of conceiving the geographical investigation. The first case emphasizes the disciplinary unity of geography, which is not affected by the existence of different areas of investigation. According to this view, geography is a disciplinary whole with many facets that correspond to specific geographical (sub-)branches. In the second case, geography is just a comprehensive label, that is the union (in terms of set theory) of different and autonomous disciplines, such as human geography, physical geography, cultural geography, and so on. This means that, according to this view, each discipline analyzes and systematizes the geographical world independently of the others, following its proper aims, as well as its specific domain of investigation, points of view, tools, and vocabulary.

Neither of the alternatives (1.1 and 1.2), however, exclude that.

1.3 the various geographical subareas may also be split so to include further areas of investigation, with different (or more specific) aims, theoretical positions, points of views, tools and/or vocabularies. And such sub-subareas of investigation represent additional perspectives on the geographical world.

Moreover, it is worth noting that, according to Munn, every act of cognitively partitioning the (geographical) world should be conceived as a "(geographical) perspective". This means that the full list of geographical perspectives is not completed by all the geographical (sub-)branches. Rather,

1.4 any theoretical position, geographical point of view, as well as any (completely) arbitrary partition of the geographical world can be regarded as a geographical perspective and, at least in principle, none of them has a privileged role on the others.

\section{Geographical Inventories}

If a (geographical) perspective draws a line between things upon which we are focusing and other things upon which we are not, one might suppose that every perspective has its own list of things: that is, a specific inventory of entities upon which the

\footnotetext{
1 About the legitimacy and the border line of the distinction between physical and human geography, see for example: Casati et al. 1998; Smith and Mark 1998; Bonnett 2008; Sala 2009; Gomez and Jones 2010; Smith 2019.
} 
perspective in question pays specific attention. Broadly speaking, we might observe that one of the key issues in making an inventory of entities consists in not neglecting the perspective (be it conceived in terms of aims, points of view, tools, and so on) we assume. That is because such a perspective can have a relevant influence on our conceptualization.

For example, if we were to draw up an inventory of the contents of a sweet box, we might be interested in the total number of sweets, classifying such sweets in accordance with their different kinds (gummies, caramels, liquorices, and so on) or with their properties (color, shape, and so forth), or maybe our interest might concern all the items (number, kinds, properties) listed before. All these possible inventories are, in principle, perfectly licit: their effectiveness will be measured by the perspective we have set. A parent who scolds her/his children after binging on sweets will be more interested in the number of sweets left in the box, compared to the confectioner producing those sweets who wishes to know which kinds of sweets are the more successful. In this sense, both the parent and the confectioner will regard the content of that box from a different perspective. Accordingly, changing our perspective might reduce the effectiveness of a specific inventory, just as it increases the effectiveness of others, and vice versa. This is why defining our perspective is so important.

Geographically speaking, things do not change: this means there can be different inventories of geographical entities (with different classes, objects, relations and so on) depending on the perspective we assume. In other words, each perspective can conceptualize, slice and systematize the geographical world in a particular way. And to be more precise, every perspective reflects its own specific domain of investigation, granularity of interest, theoretical assumptions, beliefs, faith, culture, language and so on, neglecting everything else (Bittner \& Smith, 2008; Egenhofer \& Mark, 1995; Laurini, 2017; Oakes \& Price, 2008; Smith \& Mark, 1998; Tambassi, 2018).

We could, for example, consider inventories coming from physical geography, which include entities such as mountains, lakes and oceans, and exclude items such as nations, administrative units and postal districts. On the contrary, inventories derived from human geography should not license such exclusions. However, different inventories can also emerge from the various ways in which different languages slice the geographical world. This happens with the French dichotomy between ville and cité, which is untranslatable in other languages (Sennett, 2018). Moreover, as said (1.4), a geographical perspective might also coincide with a theoretical position, with a political point of view, with arbitrary partitions and so forth. Accordingly, each specific perspective may have its own inventory. Examples of theoretical positions can be geographical realism and constructivism. According to the former, an inventory of geographical entities should presume that «geographic entities exist over and above the individuals that they appear to be related to and have the same ontological standing as these» (Casati et al., 1998: 79). An example of different perspectives based on diverse geo-political views could be the case of Italy and Bhutan on the People's Republic of China. While Italy recognizes the People's Republic of China and, therefore, includes it among the inventory of states, Bhutan does not.

And if the list of examples is not enough, we might also consider the advancements of the geographical investigation - the introduction of new tools, technologies 
and methods of research (Newman, 2006; Gwiazdzinski \& Chausson, 2015; Kolossov \& Scott, 2013; Bittner, 2019) - as well as the modifications of the geographical world itself, for example through the construction of railways, malls, or the foundation of new states. Should we not therefore consider the possibility that some of these advancements and/or modifications have introduced further perspectives on the geographical world and that, for example, the geographical inventory of an ancient roman can differ, in some respects, from contemporary inventories? (Tambassi, 2019b).

\section{Overlapping Perspectives}

To sum up, there can be, in principle, multiple and alternative perspectives on (and inventories of) the world that can be sliced, systematized and conceptualized in different ways. In the wake of some recent studies in applied ontology (Bateman \& Farrar, 2004, Grenon \& Smith, 2007, and Elford, 2012), we will call such a thesis "ontological perspectivism" and, in what follows, we will exclusively limit our discussion of ontological perspectivism to the geographical debate.

Accepting the existence of a plurality of geographical perspectives and inventories does not exclude that these alternative perspectives and inventories can overlap and/or be mutually comparable. Neither does this alleged variety exclude the possibility that the perspectives might be integrated with one another so as to generate wider accounts of the geographical world. Let us consider, for example, the entity 'lake':

3.1 What is a lake within the geographical domain?

It depends! It may be described as an area filled with water, surrounded by land, apart from any river or other outlet that flow in and out. This holds for the point of view of physical geography, which also distinguishes among tectonic, volcanic, glacial, fluvial lakes, and so forth (Hutchinson, 1957). Still, within political geography, a lake can simply be part of a nation, such as Lake Garda is part of Italy and Lake Keitele is part of Finland. More rarely, a lake can be a disputed territory, such as Lake Constance or the lake located between Malawi, Tanzania and Mozambique, also known as Lake Malawi, Lake Nyasa and Lago Niassa. Furthermore, a lake might be included within the class of communication routes in an inventory of entities of transport geography, or even within the class of tourist attractions from the perspective of tourism geography, and so forth.

Now, we could come back to question 3.1 and rephrase it in the following way:

3.2 May we describe a lake through a comprehensive/overarching geographical perspective, which combines all the (partial) geographical perspectives on the notion of lake?

3.3 Is the overarching geographical perspective an effective possibility? 
The answer to 3.3 is presumably positive. As there could be a physical perspective that is focused on entities such as neutrons and protons but not on items like trees or planets, so there can be a (overarching) geographical perspective, which pays specific attention to entities such as oceans, cities, promontories and neighborhoods (Smith \& Mark, 2001). To be more precise, according to Egenhofer and Mark (1995), such an overarching geographical perspective specifically focuses on the space in which we move around and that may be conceptualized from multiple views. And such views are (mentally) put together like a jigsaw puzzle. Moreover, according to Smith and Mark (1998), the overarching perspective specifically refers to the level of granularity that coincides with the mesoscopic stratum of spatial reality, which is the real-world counterpart of our nonscientific cognition and action in space.

\section{One, Two, Multiple Ontological Systems}

Considering the answer to 3.2, we should come back to the considerations expressed in $\S 1$ about the alternative ways of conceiving the geographical investigation.

According to 1.1, an entity such a lake might be regarded as geographically multifaceted. Consequently, all descriptions coming from physical, political, transport and tourism geography represent some particular facets. As parts of a unitary (or overarching) geographical description of that entity, those facets are just like the various properties (such as being yellow, spherical, and so on) which characterize a tennis ball. Conversely, according to 1.2 , each description of the notion of lake coming from physical, political, transport and tourism geography is completely selfsubsistent and independent from any other sector-based interpretation of the concept. However, all these descriptions can be arbitrarily put together in order to have a comprehensive geographical description of the entity 'lake', which is nothing over and above the union of the previous descriptions. Indeed, as we said earlier, each description analyzes, conceptualizes and systematizes the geographical world by following its proper aims, domain of investigation and assumptions.

Now, in both positions (1.1 and 1.2), one and the same cross-section of the geographical world can be represented by different perspectives. Even though they are different to a certain extent, those perspectives may also overlap with one another. This happens especially when they are considered from the overarching view. But if the difference between 1.1 and 1.2 in providing the overarching description of an entity such as 'lake' may seem, after all, minimal, the same difference might increase if we are going to specify what process the two positions require for the development of the ontological system behind the overarching geographical perspective. Indeed, the first alternative aims at unifying (under an overarching perspective) the various partial descriptions of the geographical world coming from the different perspectives that characterize the geographical investigation. This means that after carrying out such a task, it should be then possible to sketch the ontological system of the overarching geographical perspective (Lowe, 2006). Conversely, the second alternative considers the various geographical perspectives as completely independent. Accordingly, it does not exclude the possibility of multiple ontological 
systems encompassing the various aspects of the geographical world grasped by the diverse geographical perspectives. These multiple ontological systems, we suggest, may be subsequently integrated in the overarching geographical perspective.

\section{Ontological Integration}

Regardless of the alternative we choose, we cannot fail to notice two underlying issues raised by both the alternatives. Specifically:

5.1 How can different perspectives communicate, work together or integrate with one another, since they treat geographical partitions differently?

5.2 Is there a method or process that can provide some platform or reason for integration?

Following Barry Smith's and Bert Klagges's arguments (2008), a possible answer to this deals with the main aims of (applied) ontology as a discipline. According to the authors, ontology should not only:

5.3 draft a complete inventory of reality (or some of its parts) by specifying its hierarchical and categorial structure (see also Varzi, 2005; Tambassi, 2019a); 5.4 establish whether the whole reality can be described with one single system of categories or whether the various aspects of reality emerging from diverse areas of research need a multiplicity of ontological systems.

Rather, ontology should also:

5.5 provide some platform for the mixing, linking and integrating of different perspectives on the (in our case, geographical) world. (This should be done, I would say, in accordance to the goals we set for our inventory(ies), the (geographical) domain we want to represent and the point of view we have).

Integrating alternative perspectives on the (geographical) world might not always be that simple, given that different perspectives may also be (at least sometimes) inconsistent with each other. An example might be represented by the classification of the entity 'city', which is conceived as an object, for instance, by Sébastien Gadal (2012) and as a process by Achille Varzi (2019). But then, how to categorize such an entity? Another example might be the puzzling case of Thule and the several theories about its possible location, which include, among others, the coastline of Norway, Iceland, Greenland, Orkney, Shetland, Faroe Islands and Saaremaa (Tambassi, 2019b). Now, can we integrate all these theories about the location of Thule in a comprehensive perspective? In my opinion, we can. There is nothing to prevent ontology from integrating perspectives that are inconsistent with each other. In this case, we need not decide in favor of one or the other perspective, «provided we are careful to observe their respective functions within thought and theory» (Smith \& Klagges, 2008: 26). The communicative framework, which will enable us to navigate between 
these perspectives, should provide a theoretical basis for treating possible inconsistencies. If it does not, the resulting ontological perspective will be simply inconsistent.

However, what we cannot do, as applied ontologists, is to provide a consistent description of the geographical world when we have to integrate two (or more) perspectives that describe inconsistently the same portion of the geographical world. This is justified by the fact that ontology, as a discipline, does not have theoretical tools for choosing between two or more competing perspectives, as well as rendering such perspectives mutually consistent. Such a goal is simply outside its area of competence. In other words, applied ontology aims at providing some platform for integrating (alternative) perspectives on the (geographical) world, while choosing what perspective best describes such a world does not fall within its goals.

\section{The Two Levels of the Geo-Ontological Categorization}

As has been pointed out in $\S \S 1-2$ and 4, nothing stops us from maintaining that there can be multiple (and potentially infinite) perspectives, inventories and ontological systems, which describe the geographical world, or at least some parts of it. At this point, we might wonder if and how it is possible to outline a list of categories that specifically completes the overarching geographical perspective so as to provide the basis for the ontological system of such a perspective.

In Tambassi, 2019a, I deal with a similar issue, that is, sketching what kinds of ontological categories (Westerhoff, 2005) best complete the domain of geo-ontologies. The domain in question refers to the intersection among geography, philosophy and computer science, involving the practical application of ontological resources within the framework of the semantic web (Bishr \& Kuhn, 2000; Kuhn, 2001; Buccella et al., 2008; Fonseca \& Câmara, 2009; Tambassi, 2021). In this specific context, geo-ontologies can be considered as formal representations of general geographical concepts, aimed at describing geographical application domains or, at least, some of their very specific sub-areas. ${ }^{2}$

On this basis, the question of what categories might complete the domain of geo-ontologies is approached by thinking about such a domain as a whole being composed of two different levels of categorization. The first level is grounded on computer science and it concerns, specifically, the IT components shared among different formal ontologies: instances (or objects), classes (or kinds), relations, and slots (or properties) (Jaziri \& Gargouri, 2010; Laurini, 2017; Lord, 2010; Noy \& McGuinness, 2003). Such IT components:

6.1 reflect the state of the art of IT research (its current advancements), without excluding the possibility that further advancements could involve any change in these components;

6.2 define the final categorial structure of geo-ontologies;

6.3 tell us that every geo-ontological entity should belong to one (and only one) of them.

\footnotetext{
${ }^{2}$ In this paper, I have also remarked that some aspects of Smith's (1997), Lowe's (2006) and Cumpa's (2014) proposals might be considered as a current example of the potential usefulness of the philosophical analysis for this specific area of research.
} 
Conversely, the second level deals with contents, for which geographical analysis has the theoretical freedom to also include categories that do not appear at the first level - categories, such as modes, facts, events and so forth. Why do we need such freedom? Because we may use different perspectives for describing the geographic world. And this kind of freedom aims at guaranteeing that the contents of geo-ontologies can include a multiplicity (maybe an infinity) of geographical perspectives, which can be categorized as they are.

Now, it could be argued that not offering a clear-cut categorization at the second level may hardly seem very precise in systematizing the contents of geo-ontologies. I do not intend to diminish such a criticism. However, I also think that the possible imprecision of such a categorization would run the risk of not grasping the complexity of our ways to conceptualize differently the geographical world. In this sense, the idea behind this proposal is that the most useful service provided by the second level of categorization is to furnish an open categorial framework for best systematizing the entities emerging from different geographical perspectives, while trying to keep an open mind as to how we might interpret and conceptualize the heterogeneity of the geographical debate in its different branches and facets ${ }^{3}$ (Tambassi, 2019b).

\section{What and How to Categorize}

Getting back to the two different levels of the geo-ontological categorization, we can also add that they should not be considered as overlapping, even if they are not entirely independent. Indeed, the second level may be conceived as dependent upon the first one. More precisely, even though the (geographical) contents do not have any inclusion limit - that is, every kind of entity could be included, at least in principle, among them - IT components represent the basic and fixed structure of geoontologies within which the contents are ultimately categorized.

Figure 1 graphically summaries the process of geo-ontological categorization. Firstly, we have different inventories of entities coming from various geographical perspectives $\left(\mathrm{GP}_{1}, \mathrm{GP}_{2} \ldots \mathrm{GP}_{\mathrm{n}}\right)$. Secondly, such entities are categorized within the contents of a geo-ontology (Level 2). ${ }^{4}$ Finally, we have the IT components, which represent the final step of the entity categorization.

At this stage, one issue might be whether we really need two different (and nonoverlapping) levels of categorization for describing the geo-ontological domain.

\footnotetext{
${ }^{3}$ Neither the second level of categorization nor, more generally, this proposal have any direct application to geo-ontological building, nor do they aim to put in question or to modify the list of IT components. Rather, they are intended to remark upon the importance of a preliminary level of categorization for enhancing the systematization of the entities coming from different geographical conceptualizations within the IT components.

${ }^{4}$ The chance of homonymy among categories within the two levels of categorization does not imply that such categories necessarily denote the same entities. For instance, in Fig. 1, both levels of classification include the category "Relations". But, while at the first level "Relation" concerns the IT components, at the second level "Relations" refers to the entities that a specific geographical perspective considers as (geographic) relations: that is, entities that will be ultimately classified among one of the IT components, but not necessarily among the "Relations" of the first level (for further details, see in particular 7.3, 7.4 and 7.5).
} 


\section{Geographical Perspetives [GP]}

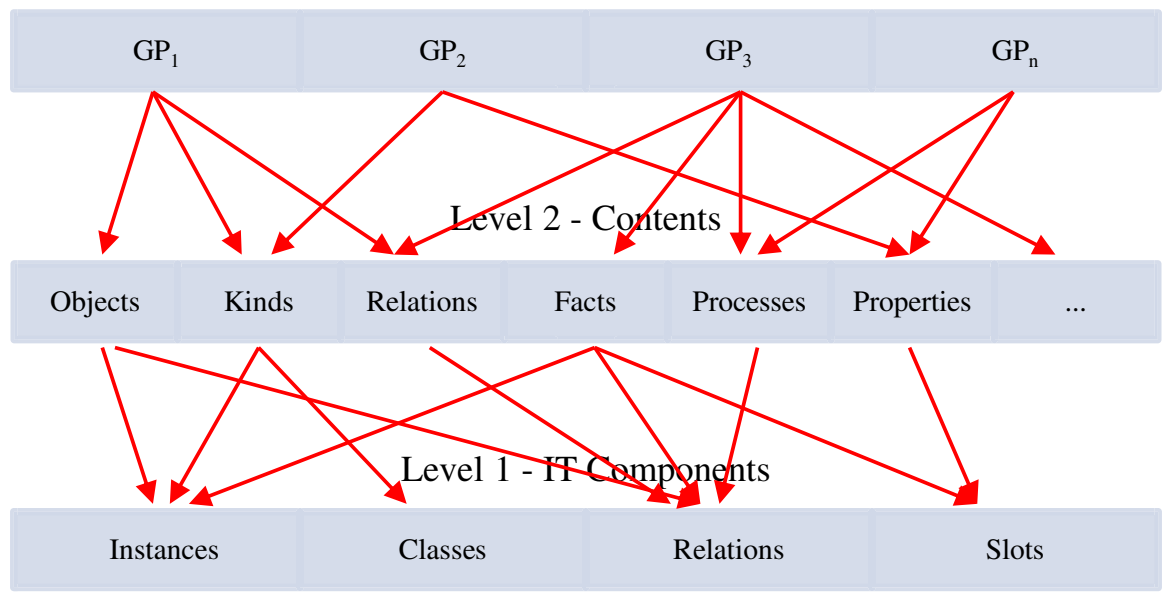

Fig. 1 A graphic example of the process of geo-ontological categorization

A possible answer could then start by emphasizing that, beside the general goals, ${ }^{5}$ every geo-ontology reflects: 1) the particular purpose for which it has been created, 2) the particular geographical domain it should represent and 3) the point of view taken by its developers. From the combination of different purposes, domains, points of view (and so forth) may derive diverse perspectives, which slice, conceptualize and/or systematize the (geographic) world that a geo-ontology has to describe. So, if the geographical entities emerging from these perspectives should be ultimately categorized within one of the IT components (first level), the introduction of the second level would ensure the possibility to choose:

7.1 how best to categorize the (geographical) entities within the IT components;

7.2 (and) what (kinds of) geographical entities we should include within the contents of our geo-ontology.

In other words, 7.2 permits our conceptualizations to involve also ontological categories which do not appear among the IT components of (geo-)ontologies. 7.1 means that while - at present - the ultimate structure of ontologies should be conceived as fixed (and resulting from the advancements of computer science), the same cannot be said for the location of the entities in such a structure.

Take for example the entity 'war'. Even if we consider such an entity as belonging to the ontological category of fact (which does not appear among the IT components of geo-ontologies), there is no reason keeping us from including it in our ontology. Indeed, 7.2 guarantees the possibility of including, among others, entities such as

\footnotetext{
${ }^{5}$ Regarding the general goals of geo-ontologies, the stakeholders of contemporary debate generally focus on the following: repeated applicability, completeness, accessibility and informativeness (Couclelis, 2019; Goy and Magro, 2015; Munn, 2008; Pâslaru-Bontaş, 2007; Tambassi, 2021).
} 
facts in geo-ontologies. Conversely, 7.1 tells us that the entity 'war' should be ultimately classified within one of the IT components of geo-ontologies (instances, classes, relations, and slots), just not what particular component. This means that we can consider the entity 'war' as, alternately:

7.3 a class of the ontology - with particular wars ('Vietnam war', 'Second world war' and so forth) as its instances;

7.4 a relation - for example a (war's) relation between two (or more) cities in a specific period of time (i.e. Rome and Carthage from 264 to $146 \mathrm{BC}$ );

7.5 a slot - for instance, the property of 'being in war' might characterize a single nation in a given period of time (i.e. Chile during 1891).

Accordingly, how best to categorize entities within the IT components (7.1) will depend, in the final analysis, upon: 1) the purpose for which a geo-ontology has been created; 2) its specific domain of investigation; 3) the point of view adopted during its development; and 4) the effectiveness of the categorization in question. In other words, 7.1 will depend upon the geographical perspective we adopt. The same goes for 7.2 for the very same reasons.

\section{Multiple Geographical Categories}

Accepting these two levels of categorization means to highlight a sort of discrepancy between two different aspects of the geo-ontological domain, namely computer science and geography. However, we should also emphasize that, according to this position, only the conjunction of these levels may complete the categorization required by geo-ontologies.

Since, as we said, the IT components represent the structure within which the geo-ontological entities are ultimately categorized, what would happen if we try to provide the categories of the overarching geographical perspective? The case is difficult because we would not have the IT components that:

8.1 provide any fixed structure to our ontological system;

8.2 impose categorial limits to the geographical domain.

Indeed, the second level (the geographical one) should not have any categorial restriction, so to retain all the ontological categories needed for systematizing the motley variety of geographical perspectives, including the overarching one. Then, if the level in question does not have categorial restrictions, as 7.1 and 7.2 remark, what should we do? Should we turn down any claim to provide specific categories for the overarching geographical perspective? We should not, or so I argue. In fact, the overarching perspective is simply expected to embrace all the entities, categories and so forth that the second level comprehends, with no exception - inconsistencies included (see $\S 5$ ). Otherwise, the overarching perspective would not be as such, but rather a geographical perspective among others. 
Finally, assuming the second level (as well as the overarching perspective) is geographically all-embracing in terms of categories (categorizations and contents) does not mean that some of its categories (categorizations and contents) cannot describe some specific (non-overarching) perspectives. And it does not mean that different groups of categories cannot be themselves the source of a multiplicity of different - even opposed - ontological systems. I find that we should not consider the opposition (and the inclusion) of different systems and categorizations as a problem. Rather, such an opposition (and inclusion) might allow us to explain why a geographical entity such as a 'city' may be conceived, when viewed from two different geographical perspectives, both as an object (Gadal, 2012) and as a process (Varzi, 2019), why some geographical inventories include some entities but not others, why there are different definitions of geographical entity (Tambassi, 2019b), why an geographical inventory in French contains different categorizations compared to the same inventory in other languages (Laurini, 2017), and so forth. In other words, our desideratum is to guarantee an ontological support for the multiplicity of perspectives, inventories, conceptualizations and categorizations of the geographical realm, as well as the legitimacy of the fact that the geographical debate can approach the question of "what there is" in the geographical world in many different ways (Vidal de la Blache, 1908, Brunhes, 1925; Bianchi, 1980; Baldacci, 1984; Cosgrove, 1990; Barnes \& Duncan, 1992; Ingold, 1993; Thrift, 1996; Robic, 1998; Nozick, 2003; Fall, 2005; Lorimer, 2005; Anderson \& Harrison, 2010; Castree, 2011; Waterton, 2013; Tanca, 2018).

\section{Conclusion}

The aim of this paper has been to discuss the ontological categories that describe the geographical world in an overarching perspective.

According to Egenhofer and Mark (1995), such a perspective should represent the mesoscopic stratum of spatial reality that may be conceptualized from multiple views, with different tools, aims, theoretical assumptions, and so forth. This means that the geographical world can be studied, sliced and systematize from a plurality of geographical perspectives, which may be put together in order to form the overarching one ( $\$ 3$ ). To achieve the overarching geographical perspective, it has been suggested that we cannot avoid integrating different (more specific) geographical perspectives and, according to Smith and Klagges (2008), applied ontology is the discipline that should provide some platform for such an integration - regardless of the fact that different perspectives can be mutually consistent ( $§ 5$ ). What is a geographical perspective then? Following Munn (2008), it has been defined as an act (any act) of cognitively partitioning the geographical world $(\S 1)$, specifying that different acts may draw different divisions between those things upon which we are focusing and those which fall outside our interest. Then, it has been pointed out that different divisions of the geographical world can give rise to different inventories of geographical entities $(\S 2)$ that, in turn, presumably require a multiplicity of ontological systems $(\S 4)$. 
The question of what categories may describe the geographical world has successively been addressed by means of the geo-ontological debate, which, however, places such a question in a wider debate, aimed at outlining what kinds of categories complete the domain of geo-ontologies $(\$ 6)$. We have seen how a possible answer to this geo-ontological issue may consist in thinking about the geo-ontological domain as a whole being composed of, at least, two different levels of categorization: IT components and geographical contents. The former constitute the final categories of geo-ontologies, within which geographical contents are ultimately systematized ( $\$$ 7). However, by focusing only on the geographical debate you can do without that part of the geo-ontological domain concerned with computer science: so, with the IT components. A categorial implication is that we can deal only with geographical contents, which do not have any categorial restriction $(\S 8)$. That means that if geographical contents are categorially all-embracing, then also the geographical perspective that should describe all these contents (the overarching perspective) shall be categorially all-embracing. And not only that: such an overarching perspective may also include inconsistencies that are derived from the different ways in which the various non-overarching perspectives conceptualize differently the geographical world. This categorial freedom is, in my opinion, what ontological perspectivism in geography (as has been described in $\S 3$ ) licenses.

As a conclusion, I want to say a few further words on ontological perspectivism, in order to reject any possible commitment to philosophical realism and relativism - as long as we conceive these two positions as two philosophical perspectives on our knowledge of the world. Against realism, we can say that allowing a plurality of perspectives on the world does not imply that we are able to grasp the world as it is. Against relativism, we find that allowing such a plurality is not an endorsement of the view that all the perspectives are veridical (or simply effective) representations of the world. I do not think that an ontological perspectivist (as such) should take a position on issues like these, even though the same ontological perspectivist could still sympathize with realistic or relativistic positions.

Funding Open access funding provided by Università degli Studi di Salerno within the CRUI-CARE Agreement.

\section{Declarations}

Conflict of Interest On behalf of all authors, the corresponding author states that there is no conflict of interest.

Open Access This article is licensed under a Creative Commons Attribution 4.0 International License, which permits use, sharing, adaptation, distribution and reproduction in any medium or format, as long as you give appropriate credit to the original author(s) and the source, provide a link to the Creative Commons licence, and indicate if changes were made. The images or other third party material in this article are included in the article's Creative Commons licence, unless indicated otherwise in a credit line to the material. If material is not included in the article's Creative Commons licence and your intended use is not permitted by statutory regulation or exceeds the permitted use, you will need to obtain permission directly from the copyright holder. To view a copy of this licence, visit http://creativecommons.org/licen ses/by/4.0/. 


\section{References}

Anderson, B., \& Harrison, P. (Eds.). (2010). Taking-Place. Non-Representational Theories and Geography. Ashgate.

Baldacci, O. (1984). Concetto di pensiero geografico e di geografia. In A. Celant \& A. Vallega (Eds.), Il pensiero geografico in Italia. (pp. 23-38). Franco Angeli.

Barnes, T. J., \& Duncan, J. S. (Eds.). (1992). Writing worlds: Discourse, text and metaphor in the representation of landscape. Routledge.

Bateman, J., \& Farrar, S. (2004). Towards a generic foundation for spatial ontology. In A. C. Varzi \& L. Vieu (Eds.), Formal Ontology in Information Systems. (pp. 237-248). IOS Press.

Bianchi, E. (1980). Da Lowenthal a Downs a Frémont: aspetti della geografia della percezione. Tip. Giorgi \& Gambi.

Bishr, Y. A., \& Kuhn, W. (2000). Ontology-based modelling of geospatial information. In A. Ostman, M. Gould, \& T. Sarjakoski (Eds.), Proceedings of the 3rd AGILE Conference on Geographic Information Science (Helsinki, pp. 24-27).

Bittner, T. (2019). Is there a quantum geography? In T. Tambassi (Ed.), The Philosophy of GIS. (pp. 209239). Springer.

Bittner, T., \& Smith, B. (2008). A theory of granular partitions. In K. Munn, \& B. Smith (Eds.), Applied Ontology. An Introduction. Ontos-Verlag.

Bonnett, A. (2008). What is Geography? . Sage.

Brunhes, J. (1925). La Géographie Humaine. Alcan.

Buccella, A., Perez, L., \& Cechich, A. (2008). GeoMergeP: Supporting an ontological approach to geographic information integration. In International Conference of the chilean computer science society. http://disi.unitn.it/*p2p/RelatedWork/Matching/bucc-perbel-cech08p.pdf.

Casati, R., Smith, B., \& Varzi, A. C. (1998). Ontological tools for geographic representation. In N. Guarino (Ed.), Formal ontology in information systems. (pp. 77-85). IOS Press.

Castree, N. (2011). Nature. In J. A. Agnew \& J. S. Duncan (Eds.), The Wiley-Blackwell Companion to Human Geography. (pp. 179-196). Blackwell.

Cosgrove, D. (1990). Realtà sociali e paesaggio simbolico. Unicopli.

Couclelis, H. (2019). Unpacking the "I" in GIS: Information, ontology, and the geographic world. In T. Tambassi (Ed.), The Philosophy of GIS. (pp. 3-24). Springer.

Cumpa, J. (2014). A materialist criterion of fundamentality. American Philosophical Quarterly, 51(4), 319-324.

Egenhofer, M., \& Mark, D. M. (1995). Naive geography. In A. U. Frank, \& W. Kuhn (Eds.), Spatial information theory: A theoretical basis for GIS. Proceedings of the second international conference (pp. 1-15). Springer.

Elford, W. (2012). A multi-ontology view of ergonomics: Applying the Cynefin framework to improve theory and practice. Work, 41(1), 812-817.

Fall, J. (2005). Michel Foucault and Francophone Geography.Circulations, conversions and disappearances. EspacesTemps.net. https://www.espacestemps.net/en/articles/michel-foucault-and-francophone-geography-en.

Fonseca, F., \& Câmara, G. (2009). Geo-ontologies. In M. Madden (Ed.), Manual of Geographic Information Systems. (pp. 157-164). American Society for Photogrammetry and Remote Sensing.

Gadal, S. (2012). Geographic space ontology, locus-object, and spatial data representation semantic theory. In T. Podobnikar \& M. Čeh (Eds.), Universal Ontology of Geographic Space: Semantic Enrichment for Spatial Data. (pp. 28-52). IGI Global.

Gomez, B., \& Jones, J. P. (Eds.). (2010). Research Methods in Geography: A Critical Introduction. Wiley-Blackwell.

Goy, A., \& Magro, D. (2015). What are ontologies useful for? Encyclopedia of information science and technology (pp. 7456-7464). IGI Global.

Grenon, P., \& Smith, B. (2007). Persistence and ontological pluralism. In C. Kanzian (Ed.), Persistence. (pp. 33-48). Springer.

Gwiazdzinski, L., \& Chausson, N. (Eds.). (2015). Urban Nights. Special issue of Journal of Urban Research, 11. https://journals.openedition.org/articulo/2595.

Hutchinson, G. E. (1957). A Treatise on Limnology, Geography, Physics and Chemistry. Wiley.

Ingold, T. (1993). The temporality of the landscape. World Archaeology, 25(2), 152-174.

Jaziri, W., \& Gargouri, F. (2010). Ontology theory, management and design: An overview and future directions. In F. Gargouri, \& W. Jaziri (Eds.), Ontology theory, management and design: Advanced tools and models. Information Science Reference. 
Kolossov, V., \& Scott, J. (2013). Selected conceptual issues in border studies. Belgeo,1. http://belgeo.revues. org/10532.

Kuhn, W. (2001). Ontologies in support of activities in geographical space. International Journal of Geographical Information Science, 15(7), 613-631.

Laurini, R. (2017). Geographic Knowledge Infrastructure: Applications to Territorial Intelligence and Smart Cities. ISTE-Elsevier.

Lord, P. (2010). Components of an ontology. http://ontogenesis.knowledgeblog.org/514.

Lorimer, H. (2005). Cultural geography: The busyness of being 'more-than-representational.' Progress in Human Geography, 29(1), 83-94.

Lowe, E. J. (2006). The four-category ontology: A metaphysical foundation for natural science. Clarendon Press.

Munn, K (2008) Introduction: What is ontology for?. In: K. Munn, \& B. Smith (Eds.), Applied Ontology. An Introduction (pp. 7-19). Ontos-Verlag.

Newman, D. (2006). The lines that continue to separate us: borders in our 'borderless' world. Progress in Human Geography, 30(2), 143-161.

Noy, N. F., \& McGuinness, D. L. (2003). Ontology development 101: A guide to creating your first ontology. Stanford University.

Nozick, R. (2003). Invarianze: La struttura delmondooggettivo. Fazi.

Oakes, T. S., \& Price, P. L. (Eds.). (2008). The Cultural Geographer Reader. Routledge.

Pâslaru-Bontaş, E. (2007). A contextual approach to ontology reuse. Methodology, methods and tools for the semantic web. Ph.D. Thesis, Department of Mathematics and Computer Science, Freien Universitat, Berlin.

Robic, M. C. (1998). L'identité nationale et ses enjeux. A propos du Tableau de la géographie de la France de P. Vidal de la Blache. Treballs de la Societat Catalana de Geografia, 48, 14, 125-137.

Sala, M. (2009).Geography. In M. Sala (Ed.), Geography. Encyclopedia of life support systems (pp. 1-56). EOLSS Publisher.

Sennett, R. (2018). Building and Dwelling: Ethics for the City. Allen Lane.

Smith, B. (1997). On Substance, accidents and universals: in defence of a constituent ontology. Philosophical Papers, 27, 105-127.

Smith, B. (2019). Drawing Boundaries. In T. Tambassi (Ed.), The Philosophy of GIS. (pp. 137-158). Springer.

Smith, B., \& Klagges, B. (2008).Philosophy and Biomedical Information Systems. In K. Munn \& B. Smith (Eds.), Applied Ontology. An Introduction (pp. 21-37). Ontos-Verlag.

Smith, B., \& Mark. D. M. (1998). Ontology and geographic kinds. In T. K. Poiker, \& N. Chrisman (Eds.), Proceedings of the Eighth International Symposium on Spatial Data Handling (Burnaby, British Columbia, International Geographical Union, pp. 308-320).

Smith, B., \& Mark D. M. (2001) Geographical categories: An ontological investigation. International Journal of Geographical Information Science, 15(7), 591-612. http://idwebhost-202-147.ethz.ch/Courses/ geog231/SmithMark_GeographicalCategories_IJGIS2001@2005-10-19T07\%3B30\%3B52.pdf.

Tambassi, T. (2018). Geo-ontologie, prospettivismo ontologico e geografia del senso comune. Semestrale di Studi e Ricerche Geografiche, 30(2), 103-116.

Tambassi, T. (2019a). What kind of ontological categories for geo-ontologies? Acta Analytica, 34(2), 135144. https://doi.org/10.1007/s12136-018-0370-7.

Tambassi, T. (2019b). What a geographical entity could be. In T. Tambassi (Ed.), The Philosophy of GIS. (pp. 177-205). Springer.

Tambassi, T. (2021). Applied Ontology of Geography. Springer.

Tanca, M. (2018). Cose, rappresentazioni, pratiche: Uno sguardo sull'ontologia ibrida della Geografia. Bollettino della Società Geografica Italiana, 14, 1(1), 5-17. https://doi.org/10.13128/bsgi.v1i1.85.

Thrift, N. J. (1996). Spatial Formations. Sage.

Varzi, A. C. (2005). Ontologia. Laterza.

Varzi, A. C. (2019). What is a city?, Topoi, 1-10. https://doi.org/10.1007/s11245-019-09647-4.

Vidal de la Blache, P. (1908). La France. Tableau géographique. Hachette.

Waterton, E. (2013). Landscape and non-representational theories. In P. Howard, I. Thompson, \& E. Waterton (Eds.), The Routledge Companion to Landscape Studies. (pp. 66-75). Routledge.

Westerhoff, J. (2005). Ontological Categories. Clarendon Press.

Publisher's Note Springer Nature remains neutral with regard to jurisdictional claims in published maps and institutional affiliations. 